\title{
Marianne Ruel, Les chrétiens et la danse dans la France moderne
}

Fatima Pilone

\section{(2) OpenEdition}

1 Journals

\section{Edizione digitale}

URL: https://journals.openedition.org/studifrancesi/46479

DOI: 10.4000/studifrancesi.46479

ISSN: 2421-5856

\section{Editore}

Rosenberg \& Sellier

\section{Edizione cartacea}

Data di pubblicazione: 1 octobre 2007

Paginazione: 494

ISSN: 0039-2944

\section{Notizia bibliografica digitale}

Fatima Pilone, «Marianne Ruel, Les chrétiens et la danse dans la France moderne», Studi Francesi [Online] 152 (LI | II) | 2007, online dal 30 novembre 2015, consultato il 24 novembre 2021. URL: http:// journals.openedition.org/studifrancesi/46479; DOI: https://doi.org/10.4000/studifrancesi.46479

Questo documento è stato generato automaticamente il 24 novembre 2021.

\section{(c) (†) $\ominus$}

Studi Francesi è distribuita con Licenza Creative Commons Attribuzione - Non commerciale - Non opere derivate 4.0 Internazionale. 


\title{
Marianne Ruel, Les chrétiens et la danse dans la France moderne
}

\author{
Fatima Pilone
}

\section{NOTIZIA}

MARIANNE RUEL, Les chrétiens et la danse dans la France moderne, Paris, Honoré Champion, 2006, pp. 563.

1 Dal 1996 Marianne Ruel insegna storia medievale e moderna al Westmont College di Santa Barbara, Stati Uniti.

2 Una certa storia della danza, tema del libro Les chrétiens et la danse dans la France moderne, implica secondo l'A. uno studio anche del corpo e delle sue rappresentazioni, delle modalità con cui esso viene percepito dall'individuo e dalla collettività. Qualsiasi uso del corpo, che sia libero esercizio o disciplina obbligatoria, lascia trasparire il modo in cui l'uomo guarda a sé stesso e come costruisce la propria identità.

3 «Sur quel pied danser», prima parte del volume, si apre con una citazione da Saint François de Sales, che riporta un pensiero tipico nei confronti della danza, quello di una lunga tradizione che la vedeva come uno strumento del diavolo: «les bals [...] attirent ordinairement les vices et pêchés qui règnent en un lieu».

4 Il quesito che si pone Marianne Ruel è quindi: danza come veleno per le anime o come rimedio contro i mali del genere umano?

5 Tuttavia, l'A. non riduce la propria analisi a una mera risposta categorica, bensì tenta di indagare il limite, spesso molto sottile, tra le diverse possibili posizioni. Certo, la prudenza ecclesiastica si contrappone all'entusiasmo di quelle che l'autrice definisce élites danzanti dell'epoca moderna, dove la prima vede il ballo come una mostruosità del corpo, mentre le seconde lo considerano una forma di apprendimento nel tentativo di controllo del corpo. 
6 In linea generale, il dibattito, secondo il punto di vista di Marianne Ruel, è essenzialmente legato a un discorso religioso e al severo controllo da parte della Chiesa, che oppone il pudore all'atteggiamento vizioso dei danzatori. In questo senso, si sottolinea l'animalità di coloro che praticano alcune danze e che sono quindi visti come individui instabili, contrapposti ai danzatori "in equilibrio", per i quali il ballo è un esercizio di armonia universale, in ogni caso sempre moderato.

7 L'A. affronta il carattere pubblico e sociale della danza, citando, ad esempio, i balli organizzati per ragazzi/e da sposare, riconoscendo nella danza stessa una componente essenziale delle feste.

8 Dopo la parte prettamente saggistica, il lettore trova una serie di Annexes: alcune tavole che classificano cronologicamente le opere consacrate alla danza e altre che riportano le citazioni bibliche.

9 Il volume si chiude con la bibliografia e l'indice dei nomi. 